\title{
Randomized controlled trial between sublingual and vaginal misoprostol for induction of labour at term \\ Original
} Article

\author{
Essam M. Sheir, Alaa Eldin H. El-Feky, Amr A. El-Sayed
}

Department of Obstetrics and Gynecology, Faculty of Medicine, Ain Shams University, Egypt

\begin{abstract}
Background: Induction of labor is an obstetrical intervention that implies stimulation of uterine contractions before the spontaneous onset of labor, with or without rupture of membranes. When the cervix is unfavorable, cervical ripening with prostaglandins to soften and open the cervix will often commenced to induce labor.

Objective: To compare $50 \mu \mathrm{g}$ of sublingual misoprostol to $50 \mu \mathrm{g}$ of vaginal misoprostol for induction of labour at term regarding efficacy and safety.

Patients and Methods: This prospective randomized controlled trial included 104 pregnant women who were recruited from Department of Obstetrics and Gynecology, Faculty of Medicine Ain-Shams University and Al-Glaa Teaching Hospital, Delivery Unit.

Results: Regarding induction-delivery interval (time from given drug for both groups to vaginal delivery), there was no significant statistical difference between both groups regarding the mean time from initial dose to the delivery. Mean $15.04 \pm 4.67$ for sublingual group versus $14.16 \pm 4.45$ for vaginal group $(P=0.331)$. As regarding fetal and maternal complications in our study, there was significant statistical difference between the vaginal and sublingual groups according to secondary outcome (hyperstimulation). The risk of hyperstimulation was higher in vaginal group ( 5 cases) compared to the sublingual group (No cases) $P=0.046$.

Conclusion: Sublingual misoprostol $50 \mu \mathrm{g}$ administered at 6 hourly intervals is as effective in promoting cervical ripening and inducing labor as vaginal misoprostol $50 \mu \mathrm{g}$ administered 6 hourly intervals as regarding induction to delivery interval, number of doses, shorter hospitalization and neonatal outcome. Sublingual misoprostol $50 \mu \mathrm{g}$ has a higher maternal and perinatal safety profile than the vaginal $50 \mu \mathrm{g}$ misoprostol including cesarean rates due to fetal distress, adverse maternal outcomes as hyperstimulation.

Recommendations: We recommend sublingual $50 \mu \mathrm{g}$ misoprostol administered at 6 hourly intervals as an efficacious and safe option for labor induction, low cost and availability is its added benefits.
\end{abstract}

Key Words: Induction to delivery interval, induction of labor, misoprostol

Received:12 January 2019, Accepted: 18 February 2019

Corresponding Author: Essam Sheir, MSc., Department of Obstetrics and Gynecology, Ain-Shams University, Tel.: 01002017409, E-mail: essamsheir@gmail.com

ISSN: 2090-7265, May 2019, Vol.9, No. 2

\section{INTRODUCTION}

Induction of labour implies artificial initiation of regular uterine contraction before their spontaneous onset, resulting in progressive effacement and dilatation of cervix, with an aim to secure safe vaginal delivery (Kreft et al., 2014).

The indication for induction has been widened in recent years and could be simplified in "labour is induced when risk of continuing pregnancy outweighs the risk of delivery." (Sheela et al., 2014).

Studies on induction of labour using different inducing agents as misoprostol, dinoprostone (PGE2) and oxytocin raised a debate on the method of induction with least side effects and high success rate (Kehl et al., 2015). Different doses, routes of administration and doses time interval had been used. In this study, we choose misoprostol (PGE2) as the inducing agent in $50 \mu \mathrm{g}$ dose every 6 hours comparing the route of administration sublingual versus vaginal (Zahran et al., 2009, Nassar et al., 2007, Caliskan et al., 2005).

Misoprostol, a synthetic prostaglandin E1 (PGE1) analogue has been studied and widely accepted as an inducing agent in different doses and routes (Chow et al., 2004). Originally, misoprostol was licensed as an oral treatment for gastric ulcers while it is used off label worldwide in obstetrics (Bartusevicius et al., 2006). Misoprostol binds 
selectively to prostanoid receptors, increases intracellular calcium and contracts myometrium while also softening the cervix by collagen disintegration and dissolution. As a result, it shortens the inductionto-delivery interval compared to placebo, oxytocin or other induction agents in women with an unfavourable cervix (Kreft et al., 2014).

\section{AIM OF THE WORK}

To compare $50 \mu \mathrm{g}$ of sublingual misoprostol to $50 \mu \mathrm{g}$ of vaginal misoprostol for induction of labour at term regarding efficacy and safety.

\section{PATIENTS AND METHODS}

This prospective randomized controlled trial included 104 pregnant women who were recruited from Department of Obstetrics and Gynecology, Faculty of Medicine Ain Shams University and Al-Glaa Teaching Hospital, Delivery Unit.

Study population: The current study included pregnant women who were presented for induction of labor with singleton pregnancy and cephalic presentation with reassuring fetal heart rate pattern and medical or obstetric indication for induction of labor.

The methods had been explained to them and only those who agreed to the procedure had been selected for the study. Patients who met the selection criteria had been informed about the advantages and disadvantages of the procedures.

\section{Inclusion criteria:}

- Primigravida, para1 or para2.

- Singleton pregnancy.

- Pregnancy duration $\geq 37$ weeks.

- Oligohydramnios (AFI $<5$ ).

- P.R.O.M (pre-labor rupture of membranes).

- Past-date pregnancy (GA $\geq 41$ weeks).

- Clinically adequate pelvis.

- Bishop score of 5 or less.

- A reactive cardiotocographics trace.

\section{The exclusion criteria:}

- Grand mutliPara

- Multiple gestations

- Malpresentation

- Non- reassuring fetal heart rate pattern.

-All patients with severe systemic illnesses like uncontrolled diabetes mellitus, severe pre-eclampsia, cardiac disease.

- Known hypersensitivity to prostaglandins.
- Any uterine anomaly or history of surgical intervention To the uterus, including cesarean delivery

-Any other maternal or fetal factors contraindicating induction of labor.

These criteria were assessed during the initial evaluation in the delivery suite as the follows:

History taking: Personal, menstrual, obstetric, past and family history was taken carefully. History of present pregnancy was taken including the first day of last menstrual period, duration of pregnancy, any warning symptoms was asked about headache, visual symptoms, edema of the face and fingers, excessive vomiting, heart burn, epigastric pain, pain in the loin, vaginal bleeding, reduced fetal movements, edema of the lower limbs ; we asked about any medication and its nature.

\section{Examination was done as:}

- General examination including: vital signs, chest, heart, and lower limb examination.

- Abdominal examination: for assessment of fundal level, presentation and position, expected fetal weight, fetal heart rate by sonicade or pinard and presence of scars of previous operation as cesarean section or myomectomy.

- Vaginal examination: and assessment of cervical position, dilatation, consistency, length and head station (Bishop's score) also condition of membranes, pelvic capacity, and to ensure presentation and position.

\section{Investigations:}

- Laboratory: blood grouping and Rh typing, complete blood count and complete urine analysis.

- Abdominal ultrasound: was done to confirm the gestational age, fetal number, viability, presentation, position and to estimate fetal weight.

- CTG: evaluation of fetal heart rate tracing for average 20 minutes.

\section{Methods of administrations:}

Demographic profile including the age, parity, gestational age, obstetric history, indication for induction and amniotic fluid volume at induction were noted. Bishop's score was assessed and non-stress test (NST) was performed before induction. Those with a Bishop's score of $\leq 5$ and with reassuring NST were included in the study. Written informed consent was taken from each patient agreed to participate in the study.

\section{Method of randomization:}

A randomization sheet developed by the computer contains 104 patients randomly assigned into 2 groups (group A and group B) each group of 52 patients. The 
randomization was concealed using the sequentially numbered opaque sealed envelop (SNOSE). One hundred and four opaque easy opening envelopes had been numbered serially, in each envelope the corresponding letter in randomization sheet was placed in one box. Pregnant women were allocated to each group according to the letter inside the envelope.

Misoprostol tablets are available as 200mg per tablet (trade name: cytotec, manufacturer: Pfizer, stored at room temperature). Each tablet was divided into 4 quadrants using a pill splitter (Apex ultra pill splitter 70068, USA), each quadrant should contain about 50mg.

Group $\boldsymbol{V}$ : Vaginal misoprostol:

One quadrant was placed into the posterior vaginal fornix and dose was repeated every six hours for a maximum of four doses or until active labor started.

Group $\boldsymbol{S}$ : Sublingual misoprostol:

One quadrant was taken sublingually. The dose was repeated every six hours for a maximum of four doses or until active labor started.

The doses were repeated till effective uterine contractions (more than 3 contractions in 10 minutes), cervical dilatations of $3 \mathrm{~cm}$ and Bishop's score of $\geq 8$ achieved. Patients were monitored for uterine contractions and fetal heart rate during this period.

PV examination was done at 6 hours and 12 hours following drug administration or earlier if the patient complained of labor pain or gush of water per vagina. Amniotomy was done when cervix is effaced with a cervical dilatation of $\geq 4 \mathrm{cms}$.

\section{Outcomes:}

The primary outcome measure was the induction to delivery interval IDI (time from inserting the drug to delivery).

Secondary outcomes included maternal and fetal outcomes:

Mode of delivery: Whether vaginal delivery or cesarean sections (the incidence of Cesarean sections for fetal distress).

Failed induction: defined as no onset of labor by the end of the induction protocol.

Uterine hyperstimulation or tachysystole.

Apgar score at 15- minutes.
Other side effects as nausea, vomiting, maternal pyrexia (maternal temperature $\geq 38$ or NICU admissions.

\section{Sample size justification:}

The required sample size has been calculated using IBM $\odot$ sample power $\bigodot$ software (IBM $\subset$ Corp., Armonk, NY, USA).

The primary outcome measure is the induction to vaginal delivery interval (IDI). The secondary outcome measure is the total number of misoprostol doses required.

A previous study reported that the mean \pm SD IDI in patients receiving sublingual or vaginal misoprostol was $13.1 \pm 4.1 \mathrm{~h}$ or $17.9 \pm 5.4 \mathrm{~h}$, respectively (Sheela et al., 2014). The mean \pm SD total number of misoprostol doses required was $1.87 \pm 0.81$ doses or $2.57 \pm 0.99$ doses in association with the sublingual or vaginal route, respectively.

So, it is estimated that a sample size of 104 patients equally randomized into either study group (52 per group) would achieve a power of $90 \%$ (beta-error, 0.1 ) to detect a statistically significant difference between the two groups as regards the total number of misoprostol doses using a two-sided student-t test with a confidence level of 99\% (type I error, 0.01).

The mean \pm SD total number of misoprostol doses is assumed to be identical and equals $2.57 \pm 0.99$ doses in both groups under the null hypothesis. Under the alternative hypothesis, the mean \pm SD total number of misoprostol doses is assumed to equal $1.87 \pm 0.81$ doses or $2.57 \pm 0.99$ doses in patients receiving sublingual or vaginal misoprostol, respectively (Sheela et al., 2014). These differences are equivalent to an effect size (Cohen d) of 0.36 .

On the other hand, a sample size of 52 patients per group would achieve a higher power of $99 \%$ (betaerror, 0.01) to detect a statistically significant difference between the two groups as regards the IDI using a two-sided student $t$ test with the same confidence level of $99 \%$ (type I error, 0.01).

The mean \pm SD IDI is assumed to be identical and equal $17.9 \pm 5.4$ in both groups under the null hypothesis. Under the alternative hypothesis, the mean \pm SD IDI is assumed to equal $13.1 \pm 4.1 \mathrm{~h}$ or $17.9 \pm 5.4 \mathrm{~h}$ in patients receiving sublingual or vaginal misoprostol, respectively (Sheela et al., 2014). These differences are equivalent to an effect size (Cohen d) of 0.44 . 
The effect size (d) is calculated as follows: $\mathrm{d}=(\mathrm{m} 1-\mathrm{m} 2) / \mathrm{sd}$ where $\mathrm{m} 1$ and $\mathrm{m} 2$ are the means of group I and group II, respectively, and sd is the common standard deviation (Chow et al., 2004).

\section{STATISTICAL ANALYSIS}

Data will be collected, tabulated then analyzed using IBMC SPPSC Statistics version 22 (IBMC Corp., Armonk, NY, USA).

Normally distributed numerical data will be presented as mean and SD and skewed data as median and interquartile range. Qualitative data will be presented as number and percentage. Comparison of normally distributed numerical data will be done using unpaired t test. Skewed data will be compared using the Mann-Whitney test. Categorical data will be compared using the chi-squared test. A two-sided p-value $<0.05$ will be considered statistically significant.

\section{RESULTS}

Table 1 shows no statistically significant difference between sublingual and vaginal according to age (years).

Table 2 shows no statistically significant difference between sublingual and vaginal according to parity.

Table 3 shows no statistically significant difference between sublingual and vaginal according to gravidity.
Table 4 shows no statistically significant difference between sublingual and vaginal according to GA (wks).

Table 5 shows no statistically significant difference between sublingual and vaginal according to indications.

Table 6 shows no statistically significant difference between sublingual and vaginal according to bishop score.

Table 7 shows no statistically significant difference between sublingual and vaginal according to no. of doses.

Table 8 shows no statistically significant difference between sublingual and vaginal with mean $15.04 \pm 4.67$ versus $14.16 \pm 4.45$, respectively according to induction to delivery interval, $p$-value $>0.05 \mathrm{NS}$.

Table 9 shows no statistically significant difference between sublingual and vaginal according to mode of delivery.

Table 10 shows statistically significant difference between sublingual and vaginal according to secondary outcome fetal/ maternal complications (hyperstimulation).

Table 11 shows no statistically significant difference between sublingual and vaginal according to Apgar score.

Table 1: Comparison between sublingual and vaginal according to age (years).

\begin{tabular}{lcccc}
\hline Age $($ years $)$ & Sublingual $(\mathrm{N}=52)$ & Vaginal $(\mathrm{N}=52)$ & t-test & $p$-value \\
\hline Mean $\pm \mathrm{SD}$ & $25.85 \pm 4.27$ & $25.21 \pm 3.86$ & 0.631 & 0.429 \\
Range & $18-36$ & $19-38$ & & \\
\hline
\end{tabular}

t-independent sample t-test

$p$-value $>0.05 \mathrm{NS}$

Table 2: Comparison between sublingual and vaginal according to parity.

\begin{tabular}{|c|c|c|c|c|c|c|}
\hline \multirow{2}{*}{ Parity } & \multicolumn{2}{|c|}{ Sublingual $(\mathrm{N}=52)$} & \multicolumn{2}{|c|}{ Vaginal $(\mathrm{N}=52)$} & \multicolumn{2}{|c|}{ Chi-square test } \\
\hline & No. & $\%$ & No. & $\%$ & $\mathrm{x} 2$ & p-value \\
\hline P1 & 16 & $30.8 \%$ & 15 & $28.8 \%$ & \multirow{4}{*}{1.175} & \multirow{4}{*}{0.759} \\
\hline $\mathrm{P} 2$ & 17 & $32.7 \%$ & 13 & $25.0 \%$ & & \\
\hline PG & 19 & $36.5 \%$ & 24 & $46.2 \%$ & & \\
\hline Total & 52 & $100.0 \%$ & 52 & $100.0 \%$ & & \\
\hline
\end{tabular}

$\mathrm{x} 2$ : Chi-square test

$p$-value $>0.05 \mathrm{NS}$ 
Table 3 : Comparison between sublingual and vaginal according to gravidity

\begin{tabular}{|c|c|c|c|c|c|c|}
\hline \multirow{2}{*}{ Gravidity } & \multicolumn{2}{|c|}{ Sublingual $(\mathrm{N}=34)$} & \multicolumn{2}{|c|}{ Vaginal $(\mathrm{N}=29)$} & \multicolumn{2}{|c|}{ Chi-square test } \\
\hline & No. & $\%$ & No. & $\%$ & $\mathrm{x} 2$ & $p$-value \\
\hline G2 & 16 & $47.06 \%$ & 15 & $51.7 \%$ & \multirow{4}{*}{5.213} & \multirow{4}{*}{0.266} \\
\hline G3 & 16 & $47.06 \%$ & 12 & $41.4 \%$ & & \\
\hline G4 & 2 & $5.90 \%$ & 0 & $0.0 \%$ & & \\
\hline G5 & 0 & $0.0 \%$ & 2 & $6.9 \%$ & & \\
\hline
\end{tabular}

$\mathrm{x} 2$ : Chi-square test

$p$-value $>0.05 \mathrm{NS}$

Table 4: Comparison between sublingual and vaginal according to GA (wks)

\begin{tabular}{lcccc}
\hline GA (wks) & Sublingual $(\mathrm{N}=52)$ & Vaginal $(\mathrm{N}=52)$ & t-test & $p$-value \\
\hline Mean \pm SD & $39.20 \pm 1.71$ & $39.66 \pm 1.83$ & 1.745 & 0.189 \\
Range & $37-43$ & $37-43$ & & \\
\hline
\end{tabular}

$\mathrm{t}$-Independent Sample t-test

$p$-value $>0.05 \mathrm{NS}$

Table 5: Comparison between sublingual and vaginal according to indication

\begin{tabular}{|c|c|c|c|c|c|c|}
\hline \multirow[t]{2}{*}{ Indication } & \multicolumn{2}{|c|}{ Sublingual $(\mathrm{N}=52)$} & \multicolumn{2}{|c|}{ Vaginal $(\mathrm{N}=52)$} & \multicolumn{2}{|c|}{ Chi-square test } \\
\hline & No. & $\%$ & No. & $\%$ & $\mathrm{x} 2$ & p-value \\
\hline GDM & 1 & $1.9 \%$ & 1 & $1.9 \%$ & 0.000 & 1.000 \\
\hline Oligohydramnios & 6 & $11.5 \%$ & 3 & $5.8 \%$ & 0.469 & 0.493 \\
\hline Pastdate & 10 & $19.2 \%$ & 16 & $30.8 \%$ & 1.299 & 0.255 \\
\hline $\operatorname{PET}(+)$ & 1 & $1.9 \%$ & 1 & $1.9 \%$ & 0.000 & 1.000 \\
\hline $\mathrm{PIH}$ & 1 & $1.9 \%$ & 5 & $9.6 \%$ & 1.601 & 0.206 \\
\hline PROM & 34 & $65.4 \%$ & 28 & $53.8 \%$ & 1.011 & 0.315 \\
\hline
\end{tabular}

$\mathrm{x} 2$ : Chi-square test

p-value $>0.05 \mathrm{NS}$

Table 6 : Comparison between sublingual and vaginal according to bishop score

\begin{tabular}{lcccc}
\hline Bishop score & Sublingual $(\mathrm{N}=52)$ & Vaginal $(\mathrm{N}=52)$ & t-test & $p$-value \\
\hline Mean $\pm \mathrm{SD}$ & $3.00 \pm 1.08$ & $2.83 \pm 0.79$ & 0.869 & 0.353 \\
Range & $1-5$ & $1-4$ & & \\
\hline
\end{tabular}

$\mathrm{t}$-Independent Sample t-test

$p$-value $>0.05 \mathrm{NS}$

Table 7: Comparison between sublingual and vaginal according to no. of doses

\begin{tabular}{|c|c|c|c|c|c|c|}
\hline \multirow{2}{*}{ No. of doses } & \multicolumn{2}{|c|}{ Sublingual $(\mathrm{N}=52)$} & \multicolumn{2}{|c|}{ Vaginal $(\mathrm{N}=52)$} & \multicolumn{2}{|c|}{ Chi-square test } \\
\hline & No. & $\%$ & No. & $\%$ & $\mathrm{x} 2$ & p-value \\
\hline 1.00 & 30 & $57.7 \%$ & 27 & $51.9 \%$ & & \\
\hline 2.00 & 16 & $30.8 \%$ & 22 & $42.3 \%$ & & \\
\hline 3.00 & 5 & $9.6 \%$ & 2 & $3.8 \%$ & 2.391 & 0.495 \\
\hline 4.00 & 1 & $1.9 \%$ & 1 & $1.9 \%$ & & \\
\hline Total & 52 & $100.0 \%$ & 52 & $100.0 \%$ & & \\
\hline
\end{tabular}

$\mathrm{x} 2$ : Chi-square test

$*$ p-value $<0.05 \mathrm{~S}$ 
Table 8: Comparison between sublingual and vaginal according to induction to delivery interval

\begin{tabular}{lccc}
\hline $\begin{array}{l}\text { Induction to } \\
\text { delivery interval }\end{array}$ & Sublingual $(\mathrm{N}=52)$ & Vaginal $(\mathrm{N}=52)$ & t-test \\
\hline Mean $\pm \mathrm{SD}$ & $15.04 \pm 4.67$ & $14.16 \pm 4.45$ & 0.954 \\
Range & $6-27$ & $7.5-28$ & 0.331 \\
\hline
\end{tabular}

t-Independent Sample t-test

$P$ value $>0.331$

Table 9: Comparison between sublingual and vaginal according to mode of delivery

\begin{tabular}{|c|c|c|c|c|c|c|}
\hline \multirow{2}{*}{ Mode of delivery } & \multicolumn{2}{|c|}{ Sublingual $(\mathrm{N}=52)$} & \multicolumn{2}{|c|}{ Vaginal $(\mathrm{N}=52)$} & \multicolumn{2}{|c|}{ Chi-square test } \\
\hline & No. & $\%$ & No. & $\%$ & $\mathrm{x} 2$ & p-value \\
\hline $\mathrm{CS}$ & 1 & $1.9 \%$ & 2 & $3.8 \%$ & & \\
\hline NVD & 51 & $98.1 \%$ & 50 & $96.2 \%$ & 0.343 & 0.558 \\
\hline Total & 52 & $100.0 \%$ & 52 & $100.0 \%$ & & \\
\hline
\end{tabular}

$\mathrm{x} 2$ : Chi-square test

$p$-value $>0.05 \mathrm{NS}$

Table 10 : Comparison between sublingual and vaginal according to secondary outcome fetal/ maternal complications

\begin{tabular}{|c|c|c|c|c|c|c|}
\hline \multirow{2}{*}{$\begin{array}{l}\text { Secondary outcome: Fetal } \\
\text { / Maternal complications }\end{array}$} & \multicolumn{2}{|c|}{ Sublingual $(\mathrm{N}=52)$} & \multicolumn{2}{|c|}{ Vaginal $(\mathrm{N}=52)$} & \multicolumn{2}{|c|}{ Chi-square test } \\
\hline & No. & $\%$ & No. & $\%$ & $\mathrm{x} 2$ & $p$-value \\
\hline None & 48 & $92.3 \%$ & 45 & $86.5 \%$ & 0.412 & 0.521 \\
\hline Fever & 2 & $3.8 \%$ & 0 & $0.0 \%$ & 0.491 & 0.483 \\
\hline Tachysystole & 1 & $1.9 \%$ & 3 & $5.8 \%$ & 0.275 & 0.600 \\
\hline Blood Transfusion & 1 & $1.9 \%$ & 0 & $0.0 \%$ & 0.011 & 0.990 \\
\hline Hyperstimulation & 0 & $0.0 \%$ & 5 & $9.6 \%$ & 4.362 & $0.046^{*}$ \\
\hline Fetal Distress & 0 & $0.0 \%$ & 1 & $1.9 \%$ & 0.011 & 0.990 \\
\hline
\end{tabular}

$\mathrm{x} 2$ : Chi-square test

p-value $>0.05 \mathrm{NS}$

Table 11: Comparison between sublingual and vaginal according to Apgar score

\begin{tabular}{lccc}
\hline Apgar score & Sublingual $(\mathrm{N}=52)$ & Vaginal $(\mathrm{N}=52)$ & z-test \\
\hline Apgar score at 1min. & $8(1)$ & $8(1)$ & 1.095 \\
Mean \pm SD & $7-9$ & $6-9$ & 0.298 \\
Range & $9(0)$ & $9(0)$ & \\
\hline Apgar score at 5min. & $8-9$ & $8-9$ & 0.624 \\
Mean \pm SD & & 0.431 \\
Range & & & \\
\hline
\end{tabular}

z-Man-Whitney test

$p$-value $>0.05 \mathrm{NS}$

\section{DISCUSSION}

Multiple clinical trials have compared the different routes and doses of misoprostol for induction of labor due to different indications, in order to show the optimal dose, the dosing regimen, the route of administration and the effectiveness of misoprostol as a wide used agent for induction of labor in current clinical practice (Nassar et al., 2007, Caliskan et al., 2005, Sheela et al., 2014, Kreft et al., 2014, Komala et al., 2013).

Other prostaglandins analogues as PGE2 (dinoprostone) used for induction of labor were not included in this study due to poor availability in the market and high cost for daily clinical practice side by 
side, several studies comparing the efficacy and safety of intravaginal misoprostol and PGE2 (dinoprostone) vaginal inserts for labor induction found no statistically significant difference between the two groups with respect to mode of delivery, indication for caesarean delivery and fetal adverse outcome (Khoury et al., 2001). Studies have been conducted comparing vaginal misoprostol with PGE2 (dinoprostone) for induction of labor in women without PROM and have found misoprostol to be equally effective (Prager et al., 2008 and Calder et al., 2008) or more effective than PGE2 with similar maternal and neonatal outcomes (Nanda et al., 2007).

Different clinical trials compared and studied different routes of administration of misoprostol to clarify both effectiveness and safety for induction of labor, most of them concluded that both sublingual and vaginal administration of misoprostol is more effective, safer, more suitable and had better maternal and fetal outcomes (Komala et al., 2013, Hofmeyr et al., 2005, Bartusevicius et al., 2005, Nassar et al., 2007).

The optimum dose of misoprostol to be used for induction of labor was studied in many clinical trials comparing $50 \mu \mathrm{g}$ and $25 \mu \mathrm{g}$ in both sublingual and vaginal routes. Most of the results of these studies showed that $50 \mu \mathrm{g}$ dose was more effective than $25 \mu \mathrm{g}$ dose (vaginal route more than sublingual); although there was less side effects in the $25 \mu \mathrm{g}$ dose (sublingual route had less side effects) and some trials compared $50 \mu \mathrm{g}$ sublingual misoprostol to 25 $\mu \mathrm{g}$ vaginally upon the previously mentioned results (Caliskan et al., 2005, Souza et al., 2008, Nassar et al., 2007, Sheela et al., 2014, Kreft et al., 2014).

In our study, both groups were demographically similar regarding maternal age, parity, gravidity, gestational age and Bishop Score; there was no significant statistical difference. (maternal age $P=0.429$, parity $P=0.759$, gravidity $P=0.266$, gestational age $P=0.189$, bishop score $P=0.353$ ).

In the present study, regarding indication for induction of labor, there was no significant statistical difference in both groups. PROM was the most common indication in both groups then past date followed by oligohydramnios (PROM $P=0.315$, pastdate $P=0.255$, oligohydramnios $P=0.493$ ).

In our study regarding induction-delivery interval (time from given drug for both groups to active phase of labor and to vaginal delivery), there was no significant statistical difference between both groups regarding the mean time from initial dose to the delivery. Mean $15.04 \pm 4.67$ for sublingual group versus $14.16 \pm 4.45$ for vaginal group $(P=0.331)$.

These results agreed by Zahran et al., in the study of 480 women divided in 2 groups of 240 each (sublingual and vaginal) The mean duration from start of induction to delivery was $17.2-3.9 \mathrm{~h}$ and $17.8-3.5 \mathrm{~h}$ for the sublingual and vaginal groups, respectively $(P=0.76)$ (Zahran et al., 2009).

These results also agreed by Caliskan et al., they suggested that induction to delivery intervals were not significantly different in their randomized controlled trial which conducted among 160 women who received $50 \mu \mathrm{g}$ of misoprostol by sublingual and vaginal routes given every 4 hours. The mean induction to delivery interval was $748+/-379 \mathrm{~min}$ in the vaginal group and $711+/-425$ in the sublingual group $(\mathrm{p}=0.56)$. The number of women delivering within $24 \mathrm{~h}$ was 73 $(91.3 \%)$ in the vaginal group and $74(92.5 \%)$ in the sublingual group $(\mathrm{p}=0.78)$ (Caliskan et al., 2005).

In the study conducted by Sheela et al., comparing $50 \mu \mathrm{g}$ of sublingual misoprostol with $25 \mu \mathrm{g}$ vaginally in 200 women ( 100 for each group) with dose interval of 6 hours, the induction to vaginal delivery interval was significantly lesser in the sublingual group, being $13.1 \pm 4.1$ as compared with $17.9 \pm 5.4$, in the vaginal group (Sheela et al., 2014).

As regarding number of doses needed in both groups, in our study, there was no significant statistical difference between both groups in the number of doses. With maximum number of doses 4 and time interval 6 hours, almost $88.5 \%$ of cases needed 2 doses in sublingual group; while about 94.2\% needed 2 doses in the vaginal group $(P=0.495)$. Both groups had the same incidence of failed induction one case in each group and both of them were a primigravida for different indications of induction of labor.

These results are not that much different from the Caliskan et al., study which conducted that the mean number of misoprostol doses required was higher in the sublingual group $(1.9 \pm 1.2)$ compared with the vaginal group $(1.1 \pm 0.4 ; p<0.001)$ with dose time interval 4 hours ( Caliskan et al., 2005).

While it was found by Sheela et al., that a statistically significant difference was seen in the total number of doses required, with the sublingual group $(50 \mu \mathrm{g})$ requiring lesser dose compared 
with the vaginal group $(25 \mu \mathrm{g}) .(1.87 \pm 0.81$ vs $2.57 \pm 0.99$ with $p<0.001$ ), a higher incidence of failed induction was observed in the vaginal group $(25 \mu \mathrm{g})$ (Sheela et al., 2014).

As regarding the mode of the delivery in our study, although there was increased risk of cesarean delivery in the vaginal group 2 cases ( 1 due to failed induction and the other due persistent fetal distress) compared to 1 case in the sublingual group (due to failed induction), there was no significant statistical difference between the two groups $(P=0.558)$.

These results are agreed by Zahran et al., the sublingual group had lower $\mathrm{CS}$ rate compared to vaginal group $(P=0.52)$, relative risk $(\mathrm{RR})$ was $0.98,95 \%$ confidence limits $0.94-1.12)$. The main indications for $\mathrm{CS}$ in both groups were fetal distress and failure to progress. However, rate of failed induction was higher in sublingual group compared to vaginal group. Seven patients in the sublingual and four in the vaginal group did not respond to the four doses of misoprostol and for each of them, CS was carried out 24 hours after starting induction (Zahran et al., 2009).

The study conducted by Caliskan et al., found the rate of CS due to fetal distress was higher in the sublingual group compared to the vaginal group. Seven cases $(8.8 \%)$ in the vaginal group and 12 cases in the sublingual group (15\%) required cesarean delivery for persistent fetal distress $(P=0.220)$ (Caliskan et al., 2005).

As regarding fetal and maternal complications in our study, there was significant statistical difference between the vaginal and sublingual groups according to secondary outcome (hyperstimulation). The risk of hyperstimulation was higher in vaginal group ( 5 cases) compared to the sublingual group (No cases) $P=0.046$. Regarding other maternal and fetal complications, there was no significant statistical difference between both groups. Though the increased incidence of tachysystole in vaginal group ( 2 cases) compared to ( 1 case) the sublingual group $(P=0.600)$ and the only case of CS due to persistent fetal distress was in the vaginal group.

These results agreed by Zahran et al. The rates of contractility disturbances, such as tachysystole were similar in the two groups, while the rate of hyperstimulation was more common in the vaginal than in the sublingual group (25 [10.4\%] vs $16[6.7 \%])$, respectively, (Zahran et al., 2009).
While Nassar et al., study conducted on 170 women divided into two groups (sublingual and vaginal) using $50 \mu \mathrm{g}$ in each of them, the mean number of tachysystole and hyperstimulation was the same in both groups with no significant statistical difference. Despite a similar proportion reporting the labour induction as more painful than expected in both groups, a significantly lower proportion mentioned that the pelvic examinations were very painful in the sublingual group (19.7 versus $36.1 \%$, relative risk [RR] $0.5,95 \%)$. Request for analgesia was similar in both groups. More women in the sublingual group thought that the labour experience was better than expected (RR 2.0, 95\%), had a positive attitude towards induction in subsequent pregnancies (RR 1.6, 95\% CI 1.) and preferred the same route in subsequent pregnancies (Nassar et al., 2007).

In the present study, as regards Apgar score at 1 and 5 minutes, there was no significant statistical different between the sublingual and vaginal groups ( $P=0.298$ and 0.431 , respectively).

These findings agreed by Nassar et al., Caliskan et al., Zahran et al., Sheela et al., (Zahran et al., 2009, Nassar et al., 2007, Caliskan et al., 2005).

\section{CONCLUSION AND RECOMMENDATION}

Sublingual misoprostol $50 \mu \mathrm{g}$ administered at 6 hourly intervals is as effective in promoting cervical ripening and inducing labor as vaginal misoprostol $50 \mu \mathrm{g}$ administered 6 hourly intervals as regarding induction to delivery interval, number of doses, shorter hospitalization and neonatal outcome. Sublingual misoprostol $50 \mu \mathrm{g}$ has a higher maternal and perinatal safety profile than the vaginal $50 \mu \mathrm{g}$ misoprostol including cesarean rates due to fetal distress, adverse maternal outcomes as hyperstimulation. We recommend sublingual $50 \mu \mathrm{g}$ misoprostol administered at 6 hourly intervals as an efficacious and safe option for labor induction with low cost and availability as its added benefits.

\section{CONFLICT OF INTEREST}

There are no conflicts of interest

\section{REFERENCES}

1. Martina Kreft, Franziska Kraehenmann, et al., (2014): Maternal and neonatal outcome of labour induction at term comparing two regimens of misoprostol. Journal of perinatal medicine 42:603-609. 
2. C. N. Sheela, C. John \& R.Preethi (2014): Comparison of the efficacy and safety of sublingual misoprostol with that of vaginal misoprostol for labour induction at term. Journal of Obstetrics and Gynaecology 35:469-471

3. S. Kehl, C. Weiss, U. Dammer, et al., (2015): Induction of labour: change of method and its effects. Geburtshilfe Frauenheilkd 75:238-243

4. Pui-Ki Chow, Szu-Yuan Chou, Chih-Fen $\mathrm{Wu}$, et al.,(2004): Efficacy of Mifepristone/ Misoprostol Combination for Medical Abortion Determined by Detection of Retained Products in a Community Hospital in Taipei, Taiwan. Taiwanese Journal of Obstetrics and Gynecology 43:77-79.

5. Zahran KM, Shahin AY, Abdellah MS, Elsayh KI. (2009): Sublingual versus vaginal misoprostol for induction of labor at term: a randomized prospective placebo-controlled study. Journal of Obstetrics and Gynaecology Research 35:1054-1060.

6. Nassar AH, Awwad J, Khalil AM, Abu-Musa A, Mehio G, Usta IM. (2007): A randomised comparison of patient satisfaction with vaginal and sublingual misoprostol for induction of labour at term. British Journal of Obstetrics and Gynaecology 114:1215-1221

7. Caliskan E, Bodur H, Ozeren S, Corakci A, Ozkan S, Yucesoy I. (2005): Misoprostol 50 microg sublingually versus vaginally for labor induction at term: a randomized study. Gynecologic and obstetric investigation 59:155-161.

8. Bartusevicius A, Barcaite E, Krikstolaitis R, Gintautas V, Nadisauskiene R. (2006): Sublingual compared with vaginal misoprostol for labour induction at term: a randomised controlled trial. British Journal of Obstetrics and Gynaecology 113:1431-1437.

9. Kambhampati Komala, Meherlatha Reddy, Iqbal Jehan Quadri, et al., (2013): Comparative Study of Oral and Vaginal Misoprostol for Induction of Labour, Maternal and Foetal Outcome. Journal of Clinical \& Diagnostic Research 7:2866-2869.

10. Khoury AN, Zhou QP, Gorenberg DM, Nies BM, Manley GE, Mecklenburg FE (2001): A comparison of intermittent vaginal administration of two different doses of misoprostol suppositories with continuous dinoprostone for cervical ripening and labor induction. $\mathrm{J}$ Matern Fetal Med; 10:186-92.

11. Prager $M$, Grimfors E E, Edlund $M$ and Marions L (2008): A randomized controlled trial of intravaginal dinoprostone, intravaginal misoprostol and transcervical balloon catheter for labor induction. BJOG; 115:1443-1450.

12. Calder A and Elder M (1992): Prostaglandins for cervical ripening and labor induction. In: Clinical application of prostaglandins: Vane JR and Grady J (ed.): in Press. Ssvsnoaks: Arnold

13. Nanda S, Singhal S R and Papneja A (2007): Induction of labour with intravaginal misoprostol and prostaglandin E2 gel: a comparative study. Tropical Doctor; 37:21-24.

14. Hofmeyr GJ and Gulmezoglu AM (2003): Vaginal misoprostol for cervical ripening and induction of labor. Cochrane Database Syst Rev; 1: CD000941.

15. Souza AS, Amorim MM, Feitosa FE (2008): Comparison of sublingual versus vaginal misoprostol for the induction of labour: a systematic review. BJOG; 115:1340-9. 